\title{
Correction to: How to count biological minds: symbiosis, the free energy principle, and reciprocal multiscale integration
}

\author{
Matthew $\operatorname{Sims}^{1}$ (D) \\ Published online: 1 December 2020 \\ o) Springer Nature B.V. 2020
}

\section{Correction to: Synthese https://doi.org/10.1007/s11229-020-02876-w}

The original article has been corrected. Several typos in the article have been corrected. Also, the Acknowledgement Section of the article has been revised. Please find here the corrected Acknowledgements.

Acknowledgements I would like to thank Dave Ward, Julian Kiverstein, Andy Clark, Mark Miller, Beren Millidge, Nina Poth, and Ben Little for their many helpful comments and fruitful conversations. Many thanks to Thomas Pradeu and all of the speakers and participants at the IDEM 2019 Symbiosis summer school for providing a lively and challenging platform for discussing many of the ideas that gave rise to this paper. I am also grateful to two anonymous reviewers for their generosity and extremely valuable suggestions.

Publisher's Note Springer Nature remains neutral with regard to jurisdictional claims in published maps and institutional affiliations.

The original article can be found online at https://doi.org/10.1007/s11229-020-02876-w.

$\triangle \quad$ Matthew Sims

s1670526@sms.ed.ac.uk

1 School of Philosophy, Psychology, and Language Sciences, University of Edinburgh, Edinburgh EH8 9AD, Scotland, UK 